\title{
Introduction: Children, AIDS and Development Policy
}

\author{
Alex de Waal, Jerker Edström and Masuma Mamdani
}

\begin{abstract}
1 Introduction
Across the hardest-hit countries of sub-Saharan Africa in particular, the HIV/AIDS epidemic is causing immense distress and impoverishment to children. Figures for the numbers of children orphaned by AIDS are commonly taken as an indicator of this impact and some 12 million African children are estimated to have lost one or both parents to the disease (UNICEF 2007). This figure serves as a headline, but in many respects it both misrepresents and understates the actual magnitude of the problem. The challenge for policy is not to reach 12 million individual children in need of assistance, but to design policies and interventions that address the diverse needs of a range of poor and vulnerable children in societies affected by AIDS, which is a far more ambitious task.
\end{abstract}

Governmental and donor responses to the crisis of children and AIDS have been woefully inadequate and the needs of children affected by AIDS have been marginalised within both development policies and AIDS programming. Alex de Waal's article in this IDS Bulletin examines why this has been so, and considers how policies and programmes for children may fare as policies shift in line with current debates on AIDS and aid. Global AIDS policy has to date focused mainly on treatment provision, human rights and prevention predominantly among adults, while placing children as a minor concern. International development strategies have concentrated on questions of economic growth and poverty reduction, while children's issues have been left out of focus. This is despite the fact that in the least developed countries, most of those who stand to benefit from social protection or poverty reducing development strategies are children.

Debates currently rage over both financing AIDS efforts and the purpose of aid more generally. One controversy centres on whether the international response to AIDS should be integrated within support to general health systems, or whether dedicated HIV and AIDS programmes and resources are in fact strengthening broader health systems through focused service and personnel improvements (Garrett 2007; Piot 2008). Another asks whether international assistance is an effective instrument for promoting economic growth and reducing poverty. Framed in such global terms, these debates can obscure the importance of focusing on children. One implication of this neglect is that while children have been ill-served by the AIDS and development assistance orthodoxies of the recent past, they - along with many other poor and vulnerable people in society - are equally in danger of being short-changed by new approaches.

Despite an increased recognition of the impacts of HIV and AIDS on children, there have been radically conflicting conceptualisations of child vulnerability in relation to the virus and epidemic (Edström 2007). A health perspective has concentrated on vulnerability to HIV infection, while a developmental approach focuses on vulnerability to the impacts of AIDS. That is, HIV can make children (and adults) vulnerable in two distinct senses, namely vulnerable to infection or to being negatively affected by its further impacts, for example in their family or social networks. These perspectives have not found common ground. But, exploring how HIV impacts on children, we also see that children play a significant role in the dynamic of the epidemic itself, particularly in Africa. A childdevelopmental approach challenges us to conceive of children as developing social agents and to understand their vulnerabilities and resilience in interrelated dynamic terms.

Addressing the challenges of children and AIDS with the seriousness warranted has far-reaching 
consequences for national and international policies. The Joint Learning Initiative on Children and AIDS (JLICA) was established in 2006 with the aim of providing the necessary foundation for evidencebased policies. It consists of four Learning Groups, concerned, respectively, with the family, the community, access to services and social and economic policies, drawn from the 'Framework for the Protection, Care and Support of Orphans and Vulnerable Children Living in a World with HIV and AIDS' (UNAIDS and UNICEF 2004). The articles in this collection derive from the research commissioned by the JLICA's Learning Group 4, on social and economic policies. This editorial introduction outlines some of the major themes pursued and draws out certain findings of the different studies with particular relevance for policy on this neglected and difficult topic.

One central finding of the JLICA as a whole is that the impacts of the HIV epidemic on outcomes for children are often specific to context and that - at a general level - they are hard to distinguish from the broader impacts of poverty, deprivation and associated social crisis (Gillespie, this IDS Bulletin; The Quality Assurance Project et al. 2008). These other factors are also important in delimiting children's lives and life chances and the HIV epidemic has now been with us so long and is so deeply embedded in social functioning of the most affected societies that the specific impacts of AIDS are often difficult to discern and even more difficult to generalise. It takes the sharpest statistical scalpel to slice the socioeconomic factors at play, so as to isolate how HIV or AIDS impacts children distinct from these other adversities, and we know that the dynamics of (often mutually reinforcing) factors of vulnerability are context specific, making general prescriptions difficult to formulate. It makes little sense at regional, national or community level to insist on privileging the increment of distress caused by this disease, yet it becomes important to understand local dynamics in order to equitably address disadvantage with a sensitivity to ensure that those affected are not excluded. Singling out those directly affected by HIV and AIDS from others can have so many undesirable (often stigmatising) side-effects that it has long been abandoned as a recommendation, if not consistently followed by practitioners in the field. We must look beyond the category 'orphans and vulnerable children' (OVCs) and respond to the diverse realities of children affected by HIV, especially those who are poor and vulnerable, in the social and economic contexts in which they find themselves.

For these and other reasons, many interventions and policies for children need to reach them through families. It is usually a mistake to frame policies with the intent of 'reaching' - assisting and protecting children outside of the context of families, kinship networks and other forms of community. Children can only be 'reached' in a context, and for the overwhelming majority of children, a family is an essential part of that context, alongside the school and community. While it may be inadvisable to attempt a firm definition of 'family' in a world of dynamic social change, and while structures of families differ widely, most family groups may share certain general common features - or 'functions' such as child-rearing, pooling resources and organising labour across domestic and public spheres (often along gendered lines). The lives of most children can best be improved through attention to better policies and supportive environments for their families and community-level services with which they regularly interact. There is a need for particular state and/or community action for the small but highly vulnerable minority of individual children who need alternative care, where no other options are available - and those children (mostly adolescents) who have left home and are vulnerable.

A further key point is that social policies for the most vulnerable children can only succeed against a backdrop of equitable universal service provision. Children affected by AIDS sometimes need targeted assistance with specific interventions, such as antiretroviral treatment for children living with AIDS; assistance with school access when parents fall seriously ill; psychosocial support and identification of appropriate alternative care in cases of orphaning, where extended family support fails; and/or legal protection in cases of dispossession or loss of inheritance rights and claims. Most affected children do not get all they need and many other disadvantaged and neglected children also need similar forms of support. There is space for individual charitable acts targeting individual children with special needs, or community-based initiatives with affected groups, but serious efforts at scale are needed to meet even the most basic of their needs. Integrated social protection programmes targeted specifically at children affected by HIV are unrealistic 
in most countries and inadvisable for reasons of equity and efficiency. The governmental, nongovernmental and community institutions in many of the most HIV-affected countries face capacity and efficiency challenges, while mounting such responses would mean spending vast financial, human and political resources in an inequitable targeting exercise - with the result that other children equally needy, but not due to AIDS, do not get any commensurate amount of help.

These findings apply equally to the most-affected southern African countries and countries with lower prevalence including those outside Africa (The Quality Assurance Project et al. 2008). The specific needs of children vary but their basic ones do not. The distinction between the poorest and less poor or middle-income countries entails different immediate priorities, reflecting different capacities for what is immediately possible.

One major finding is that HIV prevention among children is failing. Continuing transmission has distinct elements: continuing sexual transmission from adult men to adolescent girls and between adolescent girls and boys; the under-reported and under-explained infections among children aged 2-14; and vertical transmission (from mother to baby). National health systems - overstretched and under-resourced - are doing a disappointing job of preventing these HIV infections. The main concern of the articles on prevention in this IDS Bulletin is the epidemic of HIV infection among older children and adolescents in sub-Saharan Africa. In some populations, one-fifth of girls are infected with HIV and evidence and experience points to the need for structural rather than solely behavioural solutions. Many adolescents particularly girls - find themselves in social and economic contexts in which they are extremely vulnerable to sexual harassment and abuse, while many others face strong social and economic incentives for early and multiple sexual relationships. In this context, messages about behaviour change have limited relevance, not least because 'behaviour change' is an outcome rather than an intervention. What is needed is to change the circumstances in which girls and some boys are made vulnerable at school; on the way to school; at work; by pressures for early marriage; or the conditions they often face within marriage. Structural prevention measures are complex and location-specific and therefore intrinsically difficult to design, implement, monitor and evaluate (Gupta et al. 2008). They demand tackling a range of fundamentally different issues including gender inequity, social mores, poverty and vulnerability, all of which require the involvement of those most affected in the analysis and design of solutions. Despite these difficulties, we conclude that structural prevention is the way ahead to turn the tide of HIV infection.

The links between social protection for the poor and marginalised - including many children affected by HIV and AIDS - and HIV prevention for the most vulnerable adolescents, are not simple. Strengthening families, schooling and communities (including networks such as unions and voluntary associations) should result in fewer young women being placed in situations of extreme vulnerability. But, there are always some people who fall between the cracks; in some cases, economic empowerment may actually increase the vulnerability to HIV of some young women, for example as they become more involved in travel and marketing, and communities can also discriminate and stigmatise. The links between physical safety and HIV prevention are also complex. Safety is an outcome, not an intervention. The institutions and programmes responsible for physical safety, such as the police or community organisations, can themselves be a source of danger and vulnerability ( $\mathrm{ASCl} 2007)$. These observations underline the importance of designing prevention, social protection and safety measures with local participation and ownership, while also recognising that some of those most at risk of HIV are precisely those who are socially excluded and cannot easily be reached by family and communitybased efforts.

Social protection policies cannot address a major structural challenge to HIV prevention at scale. Economic policies that emphasise rapid growth, which is usually associated with urbanisation, reliance on the informal sector to employ young people, labour migration, increased transport infrastructure and mobility, tend to contribute to the social conditions which sustain high levels of HIV transmission. Social policies that entrench gender inequity do the same. We need to consider 'AIDS testing' social protection and development policies so as to make them compatible with the HIV prevention and protection needs for children and young people. 


\section{Preventing HIV infection among adolescents}

The links between poverty and HIV-related vulnerability are complex, situational and gendered, as explored by Stuart Gillespie in this IDS Bulletin. He concludes that the associations between poverty and HIV are different at national, district, community, household and individual levels. Nonetheless, some generalities can be asserted. The adverse economic impacts of HIV and AIDS on children living in affected families are substantial. Children who are already poor are further impoverished by the impacts of HIV and AIDS at the household level. Many of these families are likely to be left behind in poverty reduction driven primarily by economic growth.

Gillespie's analysis implies that most current poverty reduction or economic growth strategies will not reduce HIV in and of themselves - they will merely change its pattern. Some measures, such as education, are likely to help reduce HIV vulnerability. Other measures to promote livelihoods and increase income may in fact run the risk of increasing vulnerability to HIV among certain groups, for example economic growth policies that result in rapid urbanisation, labour migration and reliance on informal sector activities.

Richard Mabala's article on adolescent vulnerability to HIV provides a rich description of the vulnerability of the young, and in particular adolescent girls, in Dar es Salaam, Tanzania. Factors include orphanhood, migration to the city and consequent isolation from familiar social networks, forced sexual initiation, and locational effects arising from the fact that some neighbourhoods are more violent, exploitative or risky than others. All girls face constant sexual harassment and poor and vulnerable girls seek social and economic protection through transactional sexual relationships with better-off men.

Lucie Cluver and Don Operario review the evidence that children affected by AIDS face greater risks of HIV as they grow into adolescence and adulthood. They find few studies that explicitly explore this issue and still fewer that demonstrate causal linkages. On the other hand, a small number of studies do suggest correlations between orphanhood and HIV infection and sexual behaviour among orphans, but they are few and non-specific to AIDS orphans, making it hard to draw firm conclusions. However, they conclude that there is sufficient evidence to indicate that children affected by AIDS are likely to suffer long-term adverse impacts that render them more vulnerable to HIV infection later in life. This increment of vulnerability may be small and specific to certain contexts and categories, but it is real nonetheless.

Kelly Hallman's article presents quantitative evidence on sources of vulnerability to HIV among adolescents. Studies indicate that among young people in sub-Saharan Africa, poor girls, orphaned girls and boys, and socially excluded girls are the most likely to be subject to social environments that render them vulnerable and engender high risk sexual behaviours. Specifically, orphaned adolescents display higher sexual risk-taking. This risk to orphans is gendered - both by the sex of the adolescent and that of the deceased parent. Adolescent girls affected by a combination of orphaning and poverty are particularly vulnerable and at risk, suggesting that social protection for poor families should be particularly sensitive to the needs of orphans and be linked to prevention programmes to empower them in terms of sexual awareness, control and economic and social asset building. However, the vulnerability of adolescents (girls in particular) is also moderated and mitigated by social participation, inclusion in groups (which can be compromised by HIV stigma), and more cohesive neighbourhood environments. This calls for going beyond a focus on strengthening families economically, to a structural analysis whereby social protection and prevention link to the extrahousehold sphere of services, community action and social justice - particularly as the transition to adulthood involves leaving home.

\section{What makes good policy on children and AIDS?}

There is a craft to making workable policy. Too often, those who advocate for evidence-based policy overlook the fact that there is also evidence for how policy can be made to work - and it is not just a matter of advocating on the basis of evidence for how things are and what has worked to tackle them. Four articles, combining comparative and statistical analysis allow us to draw conclusions.

Debbie Budlender, Paula Proudlock and Lucy Jamieson document how policies relating to children and AIDS were developed and implemented in South Africa. They chose three policies: the child support grant (CSG); the Children's Act; and the foster care grant. The CSG is simple, targeted on the basis of income, cheap to administer, and has a high uptake rate (almost 
90 per cent). Data indicate that it has had positive impacts on outcomes on child nutrition and health, the ability of caregivers to provide essentials to children, and school enrolment. The principle of 'follow the child' is effective, especially for the kind of fractured society that South Africa has become, with many children born outside stable relationships, many absent fathers, a widening ambit of caregivers and a decline in the role of paternal kin. The main drawback of the CSG is that the amount of the grant is small. The foster care grant is, by contrast, selective and hard to access. But it does provide a much more substantial level of resources.

The Children's Act aims to give effect to a broad range of children's rights as enshrined in South Africa's constitution. It is both detailed and ambitious and its provisions reflect the input of a range of civil society organisations and also children themselves who advocate a human rights-based approach. Implementing the provisions of the Children's Act will be expensive. In the full cost scenario, services to children orphaned by AIDS take up as much as twothirds of the projected expenditures of local and provincial government.

The study by Budlender and colleagues highlights a number of key issues. Among these are the way in which policy is shaped by constitutional obligations, which run up against the constraints of budgets and human resources. Public participation has been essential to the success in passing essential legislation. The impact of the AIDS lobby has been mitigated by its lack of unity and some important victories for children affected by HIV and AIDS have been won by others, such as the disability advocates. The three examples of policymaking also demonstrate the importance of good empirical evidence produced in a relevant and timely manner, which has had an impact on policymaking.

Masuma Mamdani, Rakesh Rajani and Valerie Leach examine aspects of socioeconomic policymaking relevant to children and AIDS in Tanzania, looking at primary education reforms, the children's statute and social protection for the most vulnerable children. The article concludes that assistance to education is the most important public policy measure that brings real benefit to children affected by AIDS in Tanzania. The evidence for the effectiveness of primary education had existed for many years, but this evidence became significant for policymaking only when the policy became politically feasible. Technical solutions need political opportunities, and this requires a combination of public pressure, civil society involvement and donor support.

Like South Africa, Tanzania has long avowed its intention to enact a children's statute to provide specific effect to the relevant provisions in the Constitution and in accordance with the Convention on the Rights of the Child. After more than 20 years, this has yet to come to fruition. The delay is chiefly attributable to the social sensitivity of legislating on a complex package of child rights, including marriage and inheritance, along with the absence of an effective coordinated voice for children's rights. This implies that even if a statute is enacted, implementation is likely to be haphazard unless there is strong and consistent public pressure.

The third policy examined is assistance to Tanzania's 'most vulnerable children' (MVC) who comprise 16 per cent of the child population. A social protection programme has been mounted aiming to provide a minimum package to all MVCs. This response is fraught with problems of coordination and targeting and also delivers only very modest amounts of assistance. Local government authorities are the most important implementing stakeholders, but are constrained by insufficient resources, personnel and information, while also being overwhelmed by the multiple demands made upon them. The MVC response is reliant on a few external donors, leaving it vulnerable to donor policy shifts. Unlike universal primary education, which was a broad and explicit public concern that helped open up government institutions to popular scrutiny, the MVC programme is seen as a 'donor issue' that is remote from public engagement.

Jerker Edström, Jenne Roberts, Andy Sumner and Choub Sok Chamreun examine the drivers and obstacles in policy for children and AIDS in Cambodia. They compare the processes involved in three major policy developments, namely the Policy for Alternative Care for Children, policies on paediatric HIV treatment under the Continuum of Care and the Impact Mitigation chapter of the Second National AIDS Strategy (NSP II). In the Policy for Alternative Care for Children, change was driven by global discourses and impeded by formal institutions (with limited participation). For the development of a National OVC Plan under the 
National AIDS Strategy, progress was driven by actors and institutions (via more participatory structures), but impeded by gaps in evidence and disagreements on framing discourse. For policies on paediatric antiretroviral (ARV) treatment, strong leadership, management and consultation were crucial to success and ownership, while the specialised health sector focus, low profile and its strategically invited consultation allowed it rapid progress with less contestation.

Overall, 'children and AIDS' discourse is imported from global debates and is contested among actors and networks, constrained by lack of consensus in global policy discourse. Local research evidence is needed and increasingly being generated, but it follows rather than leads major policies. Leadership and strong management are crucial and work best when leaders invite relevant partners into the process Broad engagement is needed for stronger credibility, ownership and implementation. Leaders also need incentives and global supporters, although the latter need to be carefully managed. Working groups and task forces create iterative spaces for finding solutions and shared ownership and community voices can be supported to engage in these spaces.

The role of international actors and resources is difficult to overstate for the policy process in a country like Cambodia. Global incentives move policy and perceived corruption hinders progress. The issue of children is pushing the AIDS response towards new challenges for mainstreaming (both within and outside of the health sector) and towards intersectoral collaboration, with uncertain sustainability. Key recommendations for the future are to build on the most successful approaches to cross-sectoral including civil society - engagement, and to strengthen the participation of children and youth.

Per Strand, Mary Kinney and Robert Mattes take a complementary approach which analyses data on governance and indicators for children and AIDS for 42 sub-Saharan African countries. One striking result is the lack of causal effect on AIDS policy outcomes from most of the political variables. Neither democracy, competitiveness nor press freedom had measurable causal impacts, even indirectly, on outcomes for children. However, the analysis underlined the importance of good governance for an effective response, both in terms of general governance in the state and in the specific institutional 'architecture' of the response to AIDS. This suggests that AIDS outcomes would be enhanced by interventions to ensure general financial and political accountability in government and the bureaucracy. $A$ third finding relates to child-specific but non-AIDS-targeted policies, such as schooling and immunisation. The relationship between these two policy outcomes and governance, democracy and press freedom suggests that they are part of a political contract between democratic governments and their electorates. Overall, the study supports the case that interventions aimed at benefiting children affected by HIV and AIDS should be part of a set of welfare policies that are AIDS-sensitive in character but universal in application. Only with such a universalistic political framing of the issues can demands be freed of stigma and the supply become part of a political contract that will really work for the benefit of children affected by HIV and AIDS in Africa.

\section{Is the response affordable?}

There is no single or simple answer to the question of how much it would cost to provide protection to children made vulnerable by HIV and AIDS. No headline figure can meaningfully serve as a target sum. Neither is there a simple answer to the question of whether a developing country can support these costs.

Valerie Leach's article is based on the Tanzania country experience of a programme for assisting MVC. Noting that 40 per cent of Tanzanian children live below the national poverty line, Leach argues that it is difficult to make the case for targeting children affected by AIDS distinct from other children in need. She summarises data from Tanzanian studies which show the adverse impacts of orphaning and AIDS at household level, and which note the sad reality that households fostering children are on average poorer than those which are not. The MVC programme is targeted at the poorest of the poor and it shows that, for relatively meagre expenditures, extremes of destitution can be avoided A key point is that the Tanzanian MVC programme is small in scale and modest in impacts.

Malcolm McPherson argues that a poor country (his example is Zambia) cannot support the needs of children affected by AIDS, arguing that such an effort would be inefficient, inequitable, and unaffordable. It is better, he argues, to focus on economic growth which will benefit all. And the sheer scale of the resources required to bring all children up to the 
poverty line would surpass the total existing national and foreign aid budgets for developing countries. In the case of Zambia, the cost would be $\$ 1,000$ per child per year, or $\$ 3$ billion total annually, 43 per cent of the country's GNP. The task envisaged is nothing less than the abolition of child poverty through state welfare and implies a total bill of hundreds of billions of dollars for the African continent. Even were such resources available, McPherson argues that this would not be an appropriate way of spending the money. If aid had worked, countries such as Zambia would be wealthy by now. He argues that the reason why it has not worked is that the institutional capacity is not yet there to make good use of the resources and that the political incentives for effective expenditure do not exist.

Chris Desmond argues that much can be achieved with modest spending that falls below the expenditure ceilings which, if exceeded, would jeopardise macroeconomic stability. Moreover, the height of these ceilings depends upon the way in which money is spent. He advocates cash transfers to the poorest as representing an efficient response with minimal adverse macroeconomic effects.

Amy Nunn and Francisco Bastos make the point that, although Brazil's epidemic is smaller than those in sub-Saharan Africa and the costs of responding are commensurately lower, a key reason for the containment of the epidemic was an early and effective response, with national priorities set by Brazil itself, in important ways in opposition to international policy prescriptions. Brazil's success story may not be easy to repeat given the advanced nature of Africa's epidemics but it nonetheless has important lessons for policy elsewhere.

The articles on affordability between them raise a number of key points. First, a developing country can certainly afford some minimum package of responses. But as the response is taken to scale, issues of affordability and distortions may arise. These are manageable with good policy. Second, it is important to take a broad approach to considering the costs of responding, including the costs of not responding, including considering how these may mount as an epidemic generalises. This also raises the importance of early and serious investments in prevention for adolescents vulnerable to HIV, alongside efforts to absorb the additional socioeconomic impacts on those affected within a broader effort to enhance child welfare more generally. Third, any response involves important policy choices. There are trade-offs to a response at scale, in terms of the financial, human and institutional resources that will be allocated to the needs of children affected and made vulnerable by HIV and AIDS, which cannot be allocated to other national priorities.

\section{Findings and considerations}

The articles in this IDS Bulletin underscore the complexity of the HIV epidemics and their impacts on children, as well as the importance of factoring in the role of such children in the dynamics of the epidemic itself. Among the general themes that emerge from the analyses are the following: poverty is the backdrop to the crisis, but not itself the driver of the epidemic; inequities by age, gender, geographical origin and economic status mark vulnerabilities and create dynamic contexts where transmission can flare; it is important to define 'family' within local contexts to avoid misunderstandings; the majority of children of concern are aged 11 and older, rather than the younger children who tend to excite Western compassion; the fundamental rationale for responding is that children have rights; migrants tend to fall between the cracks; and diversity of circumstances must be acknowledged - different epidemics and different levels of income, inequality and government service provision determine different appropriate responses.

Some specific findings and considerations also emerge. One is 'break up the boxes' for children. These articles indicate that the various labels and boxes that have been in common usage do not readily translate into categories that can be used for programmatic purposes. Our research confirms the widely held view that labels such as 'orphan', OVC, $M V C$, and even CABA (children affected by AIDS) can lead to stigma and discrimination and are not useful for understanding the conditions in which children find themselves. 'Just call them children' is a useful admonition - with the reminder that the needs of boys and girls, infants and young children, school-age children and adolescents are very different and need exploring in specific contexts.

AIDS impacts matter for vulnerability to HIV infection. There are data - limited but persuasive - in support of HIV having inter-generational impacts. Some data show orphaned children to be statistically more likely to become infected with HIV in adolescence. 
Orphaning (from whatever cause of parental death) is strongly linked with higher sexual risk taking of adolescents. This sexual health risk to orphans is gendered and girls affected by both orphaning and by poverty are particularly vulnerable. However, the vulnerability of adolescents is also moderated and mitigated by social group participation outside the household.

Prevention among adolescents must focus on the social and economic context of vulnerability. Our case studies indicate that the preoccupation of the prevention debate on behavioural change misses the more important point that young people, especially girls, are vulnerable to HIV infection in the social, economic and cultural contexts in which they lack power. Structural prevention is the way ahead, although it is difficult to define and operationalise without reference to specific contexts.

The combination of policy case studies and comparative quantitative political science analysis allows us to draw important conclusions about how to make policy work, from inception to implementation. Some of the considerations that arise from the empirical findings may appear obvious but it is remarkable how rarely they are followed in practice. Many scholars and practitioners in this field are deeply knowledgeable about what can work but few pay sufficient attention to how to make it work.

- Simplicity is the first consideration. The policies at scale which are adopted most rapidly and implemented most efficiently and effectively are those which are simple - specifically those that are simple for existing national institutions.

- Political sustainability is the second consideration. Policies that are popular are likely to be easier to adopt, implement and hold to high standards. This does not imply that popularity alone should be a determining criterion as some policies (on law and order; on discrimination) that are popular or populist may be detrimental to marginalised children and adults associated with HIV. But policymakers should be attuned to the priorities expressed by the general public. A policy that allows space for popular engagement and monitoring, for example districtlevel scrutiny of budgets and spending, makes for stronger outcomes

- AIDS sensitivity is the third consideration. This refers to a policy that has a wider social goal (education; poverty alleviation) but which also addresses problems associated with HIV. It is important that where targeting is needed, for example for medical treatment, it is possible. But social protection and impact mitigation responses that are universal - or targeted according to a broader criterion, such as poverty - are generally the most progressive and cost-effective. AIDStargeted interventions are best designed and implemented against a backdrop of general service provision. Social protection policies that are stove-piped for AIDS alone are less effective.

- Process is vital. The process of arriving at a good policy is as important in determining its success as the technical content of the policy itself. The most successful policies are those that were initiated nationally (or taken control of at national level), strongly managed with transparency, with the support and involvement of civil society, and which resonate with popular priorities. Working through national systems is an ingredient of that elusive formula, national ownership, at once essential and hard to achieve. Implicit in this finding is the critique of bad process - identified as that determined by international donors using their finance and political power to leverage the adoption of particular priorities, mechanisms and practices.

The key finding of the analysis on costing is that there is no simple or 'correct' figure for what it costs to respond to the needs of children affected by AIDS. This reflects the multiple difficulties and choices involved in any costing exercise. Issues that need to be taken into account for assessing costs include the extent of targeting, the level of service to be provided, the question of whether provider costs or societal costs are to be assessed, and the importance of recognising what is already there. 


\section{References}

ASCI (AIDS, Security and Conflict Initiative) (2007) 'Expert Meeting on the Police and HIV/AIDS: Chairperson's Summary', Social Science Research Council, September

Edström, J. (2007) 'Rethinking "Vulnerability" and Social Protection for Children Affected by AIDS', IDS Bulletin 38.3: 101-5

Garrett, L. (2007) 'The Challenge of Global Health', Foreign Affairs 86.1: 1-17

Gupta, G.R.; Parkhurst, J.O.; Ogden, J.A.; Aggleton, P. and Mahal, A. (2008) 'Structural Approaches to HIV Prevention', The Lancet 372.9640: 764-75

Piot, P. (2008) 'AIDS: Exceptionalism Revisited', lecture at London School of Economics, 15 May
The Quality Assurance Project, USAID, Health Care Improvement Project and UNICEF (2008) 'The Evidence Base for Programming for Children Affected by HIV/AIDS in Low Prevalence and Concentrated Epidemic Countries', New York: UNICEF

UNAIDS and UNICEF (2004) Framework for the Protection, Care and Support of Orphans and Vulnerable Children Living in a World with HIV and AIDS, Geneva and New York: UNAIDS and UNICEF

UNICEF (2007) State of the World's Children, Geneva: UNICEF 